\title{
PALEOAMBIENTES Y USO DE LOS RECURSOS LEÑOSOS POR LOS GRUPOS CAZADORES-RECOLECTORES DEL NORESTE DE PATAGONIA DESDE EL HOLOCENO MEDIO
}

\author{
MARÍA A. MARCOS* \& FLORENCIA V. ORTEGA"
}

\begin{abstract}
RESUMEN
Los cambios ambientales ocurridos desde el Holoceno medio-tardío en la Patagonia han tenido incumbencia en las decisiones tomadas por las poblaciones cazadoras-recolectoras respecto al uso del espacio y de los recursos. En este sentido, la interacción entre la heterogeneidad del paisaje, las condiciones climáticas y el uso de los recursos por las ocupaciones humanas potencia el interés para integrar estudios palinológicos y arqueológicos en el Noreste de Patagonia. Enmarcados en proyectos de investigación arqueológica, se realizaron estudios polínicos y antracológicos en la localidad Bajo de la Quinta $\left(40^{\circ} 55^{\circ}\right.$ 42“- S, 64 20¹9“- O), costa norte del Golfo San Matías, con el objetivo de estimar las condiciones paleoambientales en el área y el uso de los recursos leñosos por las poblaciones humanas. Se reconstruyó la historia de la vegetación a partir de una secuencia fluvio-lacustre mediante el análisis palinológico. Además, en base a los carbones recuperados durante las excavaciones arqueológicas, se analizaron los recursos leñosos utilizados para el encendido de fuegos y se infirieron las estrategias de recolección de los mismos. A partir de los 3.000 años cal AP ambos registros muestran altos porcentajes de Prosopis sp., mientras que el registro antracológico señaló asimismo altos valores de Condalia sp. En contraste, hacia los 1.000 años cal AP, el registro palinológico muestra elevados valores de Schinus sp., mientras que el antracológico señala alta frecuencia de uso de Chuquiraga sp. La mayor presión de selección por parte de taxones como Condalia sp. y Chuquiraga sp. podrían vincularse a cuestiones culturales, como pautas de selección de combustible, y, en el caso de Prosopis sp. a la disponibilidad de recursos determinada por las condiciones paleoambientales.
\end{abstract}

PALABRAS CLAVE: polen, antracología, ocupaciones humanas, noreste de Patagonia.

\section{PALEOENVIRONMENTS AND USE OF WOOD RESOURCES BY HUNTER-GATHERERS OF NORTHEASTERN PATAGONIA SINCE THE MIDDLE HOLOCENE}

\footnotetext{
ABSTRACT

Environmental changes occurred during Mid-Late Holocene have had influence over the availability of resources and the Patagonian hunter-gatherer strategies on environment use. In this sense,

Laboratorio de Paleoecología y Palinología. Departamento de Biología, Facultad de Ciencias Exactas y Naturales, Universidad Nacional de Mar del Plata. Funes 3250 (CP 7600). Mar del Plata, Buenos Aires, Argentina. CONICET. e-mail: mamarcos@mdp.edu.ar. Instituto Multidisciplinario de Historia y Ciencias Humanas (IMHICIHU). Saavedra 15, 5 Piso. e-mail: qemt@hotmail.com.
} 
the interaction between landscape heterogeneity, climatic conditions and use of resources by human occupations enhances the interest to integrate archaeological and palynological studies in this region. Palynological and anthracological studies were developed in Bajo de la Quinta on San Matías Gulf northern coast $\left(40^{\circ} 55^{-} 42^{-} \mathrm{S}, 64^{\circ} 20^{-} 19^{--} \mathrm{O}\right)$, within archaeological research projects. The aim of these studies is to estimate the paleoenvironmental conditions and the kind of firewood resources used by the previous inhabitants of that area. Palynological analyses were performed, on a fluvio lacustrine sequence, to reconstruct the vegetational history of the area. Then, based on the analysis of the charcoal remains recovered during archaeological surveys, we identified the plant species that were used as firewood and we discussed the strategies employed for the recovery of the charcoal remains. Both records show that, since 3.000 cal years BP, there were high frequencies of Prosopis sp. But, the anthracological analyses alone show also high frequencies of Condalia sp. In contrast to the $1.000 \mathrm{cal} \mathrm{AP}$, the pollen record shows high values of Schinus sp., while the anthracological record shows high frequency of use of Chuquiraga sp. The greatest selection pressure by taxa as Condalia sp. and Chuquiraga sp. could be linked to cultural issues, such as fuel selection patterns, and in the case of Prosopis sp. the availability of resources determined by paleoenvironmental conditions.

KEY WORDS: pollen, anthracology, human occupations, Northeast of Patagonia.

\section{INTRODUCCIÓN}

Los cambios ambientales ocurridos desde el Holoceno medio-tardío en la Patagonia han tenido incumbencia en las decisiones tomadas por las poblaciones cazadoras-recolectoras respecto al uso del espacio y de los recursos (Borrero 1989-1990; Favier Dubois et al. 2009; Mancini 1998, 2002). En este sentido, la interacción entre la heterogeneidad del paisaje, las condiciones climáticas y el uso de los recursos por los grupos humanos en este periodo potencia el interés para integrar estudios palinológicos y arqueológicos en esta región. Diversos proyectos arqueológicos se han llevado a cabo en la costa de Patagonia Norte $\left(40^{\circ} \mathrm{S}\right)$, impulsados por la presencia de abundante registro en superficie y con la finalidad de explorar las tendencias en el uso humano del espacio y de los recursos durante el Holoceno medio y tardío (Bórmida 1964; Borella et al. 2004; Borella et al. 2007; Favier Dubois 2009; Favier Dubois et al. 2008). En el marco de estos proyectos se han realizado estudios palinológicos y antracológicos a fin de robustecer la información disponible para el área de estudio. Los registros polínicos han indicado condiciones áridas durante el Holoceno medio y un cambio ambiental hacia condiciones semiáridas a partir de los 3.000 años cal AP (Marcos et al.2011, 2012). Esta información permitió estimar cuál fue el escenario paleoambiental en el cual han vivido los grupos cazadores-recolectores del área desde el Holoceno medio. Además, Ortega \& Marconetto (2011) plantearon un modelo de la vegetación actual cuyo objeto fue proponer un escenario en el cual los cazadores recolectores se movieron en búsqueda de recursos combustibles. Al contrastar el registro antracológico con este modelo, se observó que la diversidad florística del ambiente no se asemejaba a aquella registrada en los carbones. Esto las llevó a pensar en la posibilidad que la selección de especies leñosas haya tenido un papel importante en la conformación del registro antracológico. La incorporación de la información aportada por los análisis polínicos, permitió reforzar el modelo florístico/ambiental en el cual se habrían movilizado los cazadores-recolectores del área de Bajo de la Quinta utilizaron los recursos (Marcos \& Ortega 2011).

El presente trabajo multidisciplinario es una continuación de los trabajos previos y aportará información valiosa para reconstruir la historia del paleoambiente. Además, permitirá inferir la forma en que los cambios ambientales afectaron la oferta de los recursos leñosos, lo cual pudo haber incidido en las estrategias de recolección utilizadas por los grupos cazadores-recolectores del área.

Los objetivos de este estudio son (1) reconstruir los cambios ambientales ocurridos desde el Holoceno medio en el noreste de Patagonia y (2) analizar pautas de selección de combustible en base a la oferta ambiental y/o cuestiones culturales en la selección de los recursos leñosos entre los 3.000 y 


\subsection{0 años cal AP.}

\section{ANTECEDENTES ARQUEOLÓGICOS}

A fines de 2003 se iniciaron proyectos de investigación arqueológica a fin de actualizar los estudios realizados por Bórmida en 1964 y estudiar el uso de este espacio rico en evidencia arqueológica, su correlato ecológico-ambiental y su relación con la disponibilidad de recursos para los cazadores-recolectores terrestres (Favier Dubois \& Borella 2011). A partir de un relevamiento preliminar de la costa del Golfo San Matías, Argentina, se determinó la intensidad de la señal arqueológica a lo largo de la faja litoral, siendo la costa norte la más utilizada (Favier Dubois et al. 2008). En los sitios arqueológicos de esta costa se halla representada la explotación de moluscos, evidenciada en los recurrentes concheros. Esta mayor densidad de la señal arqueológica es explicada por los frecuentes entrantes marinos que favorecen la accesibilidad a recursos faunísticos, además de la presencia de recursos críticos como el agua, reparos topográficos y recursos líticos (Favier Dubois \& Borella 2011).

En base al registro bioarqueológico recuperado en este litoral se han realizado estudios paleodietarios sobre restos humanos detectándose dos períodos principales en el uso de los recursos marinos. El primer período corresponde al uso intensivo de los mismos entre los 6.000 y los 2.100 años cal AP, al cual puede vincularse la evidencia arqueológica de pesca intensiva entre los ca. 5000 y 6000 años cal AP (Favier Dubois et al. 2009; Scartascini et al. 2009; Favier Dubois y Scartascini 2011). El segundo período (1.500-400 años cal AP) está caracterizado por una dieta mixta (marina -terrestre) y continental, con el consumo de especies de menor nivel trófico en promedio (Favier Dubois et al. 2009).

La evidencia arqueológica en la localidad Bajo de la Quinta se encuentra ubicada sobre concheros entre las dunas, a diferentes distancias de la playa actual. De las excavaciones de estos concheros se recuperaron numerosos restos bioarqueológicos correspondientes a entierros primarios y secundarios, restos zooarqueológicos, materiales líticos y carbones, entre otros hallazgos (Favier Dubois \& Borella 2007).

\section{CARACTERISTICAS GENERALES DEL ÁREA DE ESTUDIO}

La extrema aridez del este de Patagonia Norte está relacionada con la dominancia del sistema de los vientos del oeste y la topografía del continente. Estos vientos contienen masas de aire húmedo originados en el Pacífico que se descargan al pasar la cordillera estableciéndose un marcado gradiente de precipitación en dirección oeste-este (Garreaud et al. 2013). Además, la localización de la banda extratropical de los vientos del oeste cambia su posición estacionalmente. Debido a esto, la región costera del noreste de Patagonia recibe precipitaciones en primavera y verano cuando los vientos del oeste y el Anticiclón Subtropical del Atlántico se debilitan y las masas de aire húmedo de los vientos del este penetran el continente (Schäbitz 2003). La zonación de la vegetación es concordante con este gradiente de precipitación (Roig 1998). En este sentido, la interpretación de indicadores biológicos como el polen en el registro fósil han permitido inferir cambios en las comunidades vegetales asociados a cambios climáticos. Particularmente para el centro y este de Patagonia norte, cambios en la dominancia de los vientos del oeste o del este han sido asociados a mayor o menor aridez que se reflejan en los tipos polínicos presentes en los registros polínicos (Marcos et al. 2011, 2012; Schäbitz 1994, 2003; Schäbitz \& Liebrich, 1998).

Bajo de la Quinta (405 $55^{-} 42^{--S}$; $64^{\circ} 20^{\prime}$ $19^{--O}$ ) es un "bajo" con una superficie aproximada de $7 \mathrm{~km}^{2}$ que se encuentra ubicado en el noreste de Patagonia (costa norte del golfo San Matías). El área es de origen fluvial y de deflación, labrada sobre sedimentos del terciario (Mioceno) presenta acantilados activos de $15 \mathrm{~m}$ de altitud así como cordones litorales de edad Pleistocena y Holocena (Kokot et al. 2004; Favier Dubois \& Kokot 2011). Actualmente, el drenaje hacia el mar de la cuenca se encuentra impedido por cordones de playa y por la formación de dunas, como consecuencia, esporádicas lluvias en la región generan una pequeña laguna temporaria en el sector del drenaje interrumpido (Fig. 1) (Favier Dubois \& Kokot 2011). La región está caracterizada por un clima semiárido, con una temperatura de $12^{\circ} \mathrm{C}$ y precipitaciones que varían entre 100 y $350 \mathrm{~mm}$ 
anuales (Labraga \& Villalba 2009).

\section{Vegetación actual}

La vegetación es de tipo arbustiva perteneciente a la provincia biogeográfica del Monte, distrito Sur o Austral (Roig-Juñent et al. 2001; Abraham et al. 2009; Roig et al. 2009). Las comunidades dominantes son las estepas arbustivas de Larrea sp. o jarillares. Entre la vegetación acompañante se encuentra el Alpataco (Prosopis alpataco), Chañar (Geoffroea decorticans), Mata de sebo (Monttea aphylla), Olivillo (Hyalis argentea) y Junquillo (Sporobolus rigens), cuya presencia está determinada por factores edáficos, constituyendo asociaciones de especies adaptadas a condiciones azonales con suelos salinos, arenosos o anegados (Morello 1958). A nivel local, se han diferenciado cuatro comunidades vegetales (Comunidad psammófita, Comunidad de transición psammófita-arbustiva, Estepa arbustiva y Estepa graminosa) en base a las unidades geomorfológicas asociadas (Marcos \& Mancini 2012). Diferentes unidades geomorfológicas fueron descriptas por Favier Dubois \& Kokot (2011) en Bajo de la Quinta. La unidad geomorfológica Dunas Móviles se encuentran representadas por un campo de dunas barjanoides que corren en dirección Este-Oeste, cuya vegetación es únicamente psammófita. Las Dunas Fijas presentan vegetación graminosa-arbustiva y sustrato limo-arenoso. En los alrededores de las dunas se ubica la unidad geomorfológica con suelo limo-arcilloso y cuya fisonomía dominante es la estepa arbustiva. Por último, la unidad geomorfológica Laguna Efímera, que se encuentra ubicada entre las Dunas Fijas y el Paisaje Fluvial, presenta un terreno plano con suelo limoso y vegetación graminosa (Marcos \& Mancini 2012).

\section{MATERIALES Y MÉTODOS}

Análisis polínico, sedimentológico yestratigráfico

Se realizó el análisis polínico de 45 muestras a intervalos continuos de $5 \mathrm{~cm}$ en un perfil fluviolacustre de $2.20 \mathrm{~m}$ de profundidad excavado en el borde de la laguna seca presente en Bajo de la Quinta. La extracción de los granos de polen se realizó mediante las técnicas estándar (Gray 1965; Faegri \& Iversen 1989; Bennett \& Willis 2001). Se tomaron aproximadamente entre 5 y $7 \mathrm{~g}$ de sedimento y se agregaron a cada muestra 3 pastillas con esporas de Lycopodium clavatum

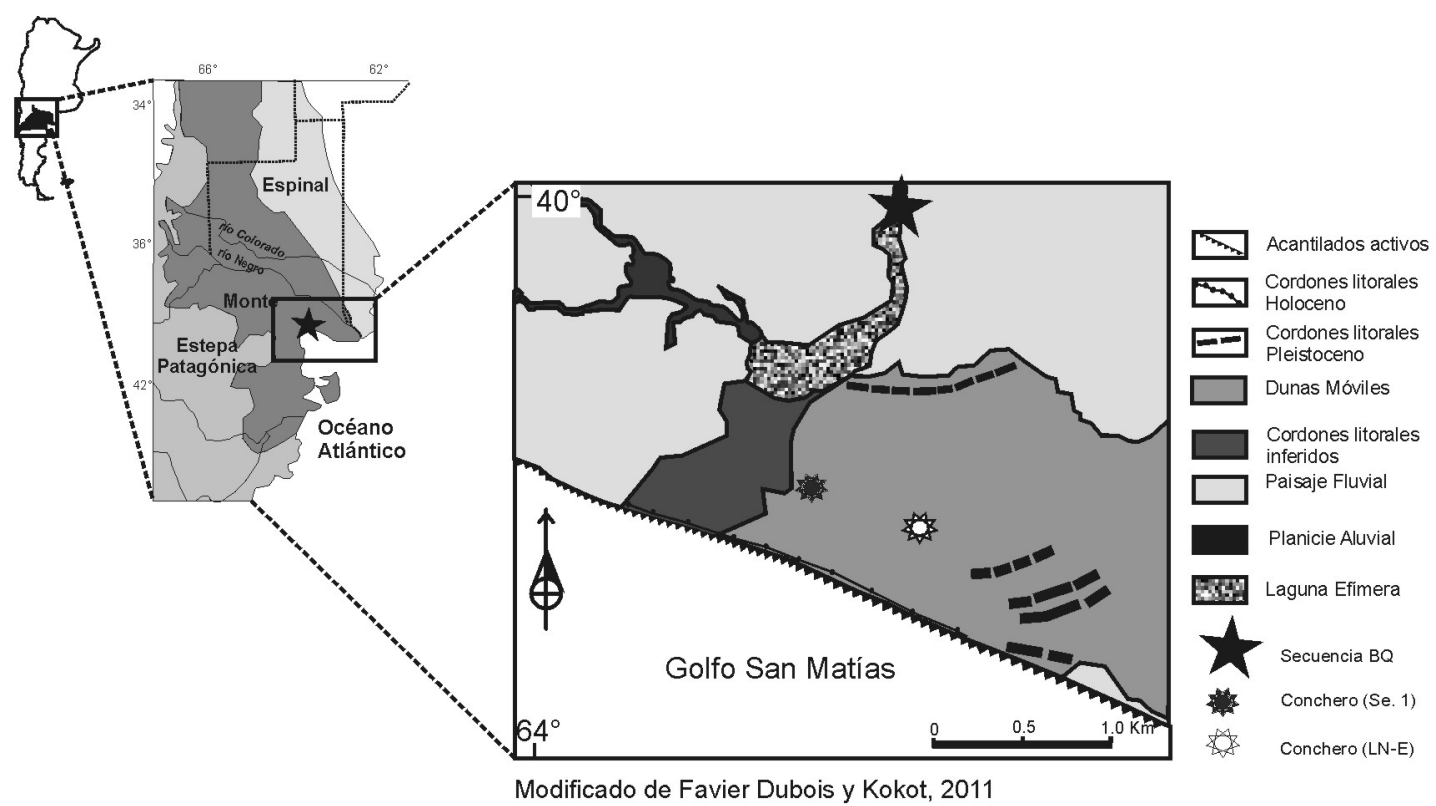

Fig. 1 Ubicación del sitio de estudio, Bajo de la Quinta, Río Negro, Argentina. Unidades geomorfológicas, secuencia BQ y concheros (Se. 1 y LN-E) presentes en Bajo de la Quinta. 
para el cálculo de la concentración polínica (Stockmarr 1971) y de la suma polínica mínima representativa (Bianchi y D’Antoni 1986). El tratamiento físico-químico consistió en el filtrado por malla de $120 \mu \mathrm{m}$, defloculación de las arcillas y eliminación de ácidos húmicos con $\mathrm{KOH}$ (10\%) en baño térmico durante 10 minutos. Los carbonatos fueron eliminados con $\mathrm{HCl}$ (10\%), la fracción orgánica fue separada de la mineral con líquidos pesados $\left(\mathrm{ZnCl}_{2} \delta=2 \mathrm{~g} / \mathrm{cm}^{3}\right)$ y se eliminaron los silicatos con HF durante 24 hs. Por último, el material orgánico celulósico se eliminó mediante una mezcla acetolítica $\left(90 \% \quad\left(\mathrm{CH}_{3} \mathrm{CO}\right)_{2} \mathrm{O}, 10 \%\right.$ $\mathrm{H}_{2} \mathrm{SO}_{4}$ ). Las muestras fósiles de la secuencia fueron ordenadas en los diagramas polínicos de acuerdo con su posición estratigráfica. Los resultados de los recuentos polínicos se expresan en porcentajes de la suma total en la Figura 3 (TGView 2.0.2, Grimm 2004). Los tipos polínicos Geraniaceae, Ranunculaceae, Convolvulaceae, Malvaceae, Plumbaginaceae y Rosaceae fueron agrupadas como "hierbas", Celtis, Nothofagus y Podocarpus como "larga distancia", Lycium, Chuquiraga, Bougainvillea, Geoffroea y Verbenaceae como "otros arbustos", Caesalpinoideae y Lammiaceae como "subarbusto" y Hyalis argentea y Calycera crassifolia como "tipos psammófitos".

La descripción estratigráfica de la secuencia fue hecha en campo diferenciándose los principales cambios estratigráficos (Dr. Favier
Dubois, com. pers.). La unidad superior $(0-35 \mathrm{~cm})$ presenta sedimentos laminados correspondientes a depósitos de decantación de la laguna. La unidad inferior, hasta los 220, cm corresponde a depósitos finos producto de la inundación periódica del bajo. La misma se puede subdividir en dos partes: la superior $(35-115 \mathrm{~cm})$ presenta sucesivos horizontes A de suelo de diferente desarrollo relativo; la parte inferior $(115-220 \mathrm{~cm})$ no registra eventos pedológicos y presenta algunos niveles horizontales limo-arcillosos y arenosos. Por otro lado, se destacó la presencia de moteados salinos desde la superficie hasta el nivel $150 \mathrm{~cm}$ y de pequeñas concreciones de yeso entre los 195 y $220 \mathrm{~cm}$ de profundidad. Para el análisis de contenido de materia orgánica y de carbonatos de las muestras de sedimento fósil se utilizaron los mismos niveles de sedimentos que para el análisis polínico. Las muestras fueron secadas en una estufa a $105^{\circ} \mathrm{C}$ toda la noche y posteriormente quemadas en una mufla a $500^{\circ} \mathrm{C}$ (4 hs) y $950^{\circ} \mathrm{C}$ (2 hs) respectivamente (Bengtsson \& Enell 1986; Heiri et al. 2001). Los resultados se expresan como porcentajes de la pérdida de peso de los sedimentos en relación con el peso seco de las muestras antes de la combustión (Heiri et al. 2001). El control cronológico fue realizado mediante tres dataciones radiocarbónicas (Tabla 1) calibradas mediante el programa CALIB 6.0.2 (Stuiver \& Reimer 1993; Stuiver et al. 2005) utilizando la curva de calibración del Hemisferio Sur

Tabla 1. Fechados radiocarbónicos de columnas polínicas analizadas y de carbones procedentes de excavaciones realizadas en Bajo de la Quinta (Favier Dubois et al. 2009; Favier Dubois \& Kokot 2011; Marcos et al. 2011).

\begin{tabular}{|c|c|c|c|c|c|}
\hline Sitio & Profundidad $(\mathrm{cm})$ & $\begin{array}{l}\text { Edad }{ }^{14} \mathrm{C} \\
\text { (años AP) }\end{array}$ & $\begin{array}{c}\text { Años calibrados } \\
\text { (cal. AP) }{ }^{* *}\end{array}$ & Material & $\begin{array}{c}\text { Referencia de } \\
\text { laboratorio }\end{array}$ \\
\hline BQBL & $40-41$ & $662 \pm 65$ & 603 & sedimento & AA88053 \\
\hline BQBL & $71-72$ & $970 \pm 25$ & 849 & sedimento & UGAMS8892 \\
\hline BQBL & $110-111$ & $2767 \pm 93$ & 2834 & sedimento & AA88052 \\
\hline BQ Sector 1 & -- & $3077 \pm 54$ & 3110 & $\begin{array}{l}\text { M3 sup. y } \\
\text { premolar }\end{array}$ & AA64777 \\
\hline BQ Sector 1 & -- & $3000 \pm 90$ & 3224 & Valvas* & LP-1878 \\
\hline BQ Sector LN-E & --- & $1070 \pm 60$ & 929 & Valvas* & LP-2016 \\
\hline
\end{tabular}

*En las edades sobre valvas marinas se utilizó el valor local de efecto reservorio de $266 \pm 51$ años AP en su calibración (Favier Dubois 2009).

***Programa CALIB REV 6.0.0 (1986-2005 M. Stuiver \& P.J. Reimer). Edades calibradas en años AP a un sigma y utilizando la curva para el Hemisferio sur. 


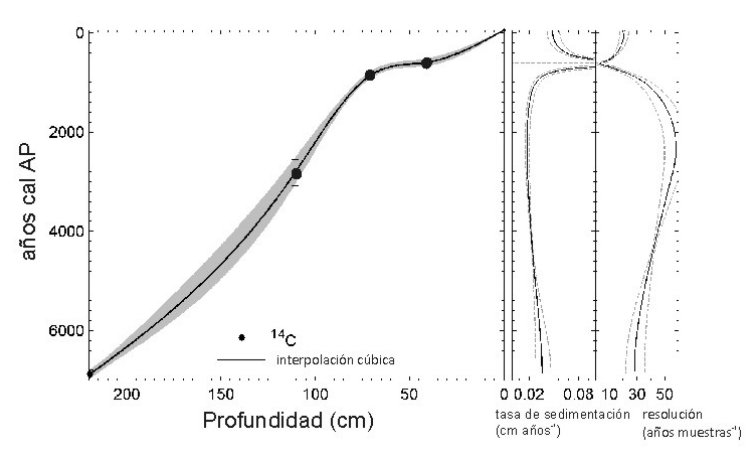

Fig. 2 Modelo de edad de la secuencia sedimentaria BQ.

(McCormac et al.; 2004, Reimer et al. 2004). La base de la secuencia se correlacionó de acuerdo al modelo de edad realizado para otra secuencia de la misma laguna, utilizando los fechados disponibles y los principales cambios estratigráficos (Marcos et al. 2012). Se realizó un modelo de edad para la secuencia fósil mediante el cual se estimaron los rangos temporales para cada zona polínica (Fig. 2). La reconstrucción paleoambiental se realizó en base al modelo polínico actual de lalocalidad (Marcos \& Mancini 2012). La tasa de sedimentación de la secuencia fue de $0,02 \mathrm{~cm}_{\text {año }}{ }^{-1}$.

\section{Análisis antracológico}

Para el análisis antracológico la colección de referencia de plantas leñosas fue confeccionada para el área de estudio con especies locales (Ortega \& Marconetto 2009). La misma está compuesta por 37 especies leñosas que crecen en la actualidad en la región de estudio Esta muestra pertenece al Departamento de Investigaciones Prehistóricas y Arqueológicas (DIPA-IMHICIHU) y al Laboratorio de Arqueología del Museo de Antropología (UNC). De los leños se obtuvieron cortes histológicos en los tres planos anatómicos de la madera (transversal, longitudinal tangencial y longitudinal radial) y éstos se observaron en un microscopio óptico con luz transmitida a 40X, 100X y 400X para realizar la descripción de la morfología de cada uno de ellos. Para realizar la descripción de los caracteres diagnósticos se utilizaron claves taxonómicas (IAWA 1964, 1989) y bibliografía (Tortorelli 1956; Castro 1994; Ancibor \& Pérez de Micou 1995, 2002; Piqué i Huerta 1999). Una vez identificados los caracteres diagnósticos de cada uno de los leños se pasó a la observación del carbón arqueológico. Cada carbón es analizado realizando cortes frescos en los tres planos anatómicos y observándolos al microscopio óptico con luz incidente, a 40X y 100X. Se registran los caracteres diagnósticos y se comparan con aquellos de la muestra de referencia. Esta metodología se puede utilizar ya que, luego de la combustión, la estructura anatómica de los leños se mantiene (Vernet 1973). Si bien se pueden presentar grietas por la exposición a altas temperaturas, la estructura anatómica de la madera (es decir, la morfología, cantidad y disposición de las células del tejido xilemático) no se ve alterada, con lo cual es posible identificar a qué género pertenece el leño luego de su carbonización (Smart y Hoffman 1988; ver Castro 1994, para una discusión acerca de la dificultad de llegar a nivel de especie a través del análisis del leño).

Antes de pasar a la descripción de los conjuntos analizados y los resultados obtenidos, es necesario aclarar diferentes cuestiones relacionadas con la metodología de análisis, la cual se encuentra altamente condicionada por las características del material a analizar. En primer lugar, el volumen de carbón recuperado difiere de conjunto a conjunto, por lo cual, en repetidas ocasiones, fue necesario recurrir a diferentes técnicas de muestreo. Cuando el material es escaso, y el tamaño de los carbones lo permite, se procede al análisis del conjunto en su totalidad; cuando el volumen de carbón es muy abundante, se utiliza la curva de riqueza especifica: se analizan carbones hasta que no aparecen géneros nuevos y la curva se estabiliza (ver Piqué i Huerta 1999, para una discusión acerca del número mínimo de carbones a analizar; Marconetto 2005). En segundo lugar, y retomando el tema del tamaño de los carbones, cuanto más pequeños son los fragmentos a analizar, más se dificulta la identificación. Se ha postulado como tamaño mínimo aquellos carbones de $5 \mathrm{~mm}$ de lado (Piqué i Huerta 1999). Los carbones de este tamaño en adelante son fácilmente fracturables en sus diferentes planos anatómicos, y los cortes obtenidos proporcionan una superficie lo suficientemente amplia para observar en el miscroscopio, superficie donde los caracteres diagnósticos son discriminables al observarlos al microscopio. Sin embargo, los procesos deflacionarios y tafonómicos (Favier Dubois \& Borella 2007; Favier Dubois et al. 2008, 
Manzi et al. 2009) que actuaron y actúan sobre los concheros analizados, afectaron a los conjuntos antracológicos recuperados, en muchos casos favoreciendo la fragmentación de los carbones. Esto hizo necesario, en aquellos conjuntos cuyos carbones presentan tamaños menores a $5 \mathrm{~mm}$, observar fragmentos de hasta $3 \mathrm{~mm}$, pero, aún así, con muy buenos resultados. Por último, la unidad de análisis utilizada es el volumen de cada uno de los géneros identificados, el cual es medido en centímetros cúbicos. El volumen es la medida más representativa de la frecuencia de uso de los leños que se observan en los conjuntos. Esto se debe a que los taxones más utilizados son los que tienen más probabilidad de dejar una cantidad mayor de residuos luego de la combustión (Piqué i Huerta 1999).

Se realizó el análisis antracológico de cuatro conjuntos carbonosos procedentes de dos sectores diferentes de la localidad arqueológica de Bajo de la Quinta, el sector 1 (Se. 1) y el sector La Noria-Este (LN-E). Se analizaron un total de 156 carbones que sumaron un volumen total de 93,9 ml. Del Se. 1 , cuyos fechados son de 2788 y 3137 años cal $\mathrm{AP}$, se analizó carbón procedente de tres sondeos diferentes, sondeos 1, 2 y 2/B. Del sector LN-E se analizó un conjunto carbonoso de 929 años cal AP.

El conjunto carbonoso procedente del sondeo 1 del Se. 1, presentaba un solo estrato de material y, dada la escasez de carbón en dicho estrato, éste se analizó en su totalidad. De este conjunto se analizaron 16 carbones, que sumaron un total de $4 \mathrm{ml}$ de volumen. Dentro del mismo sector, los sondeos 2 y $2 / \mathrm{B}$ presentaron mayor potencia de material y se recuperaron carbones en dos estratos (N1 y 2). Estos conjuntos antracológicos fueron muestreados utilizando la curva de riqueza, atendiendo a las características de material en cuanto a tamaño de los carbones. En consecuencia, del sondeo 2 se analizaron 42 carbones (31 ml) y del sondeo 2/B 36 fragmentos (40 ml). Por último, del sector LN-E, cuyo sondeo también se compone de dos niveles, se obtuvo abundante material antracológico, pero con fragmentos de pequeño tamaño. Con lo cual, al igual que en los sondeos 2 y $2 / \mathrm{B}$ del Se. 1 , se muestreó siguiendo la curva y se analizaron 62 fragmentos de carbón, en su mayoría de entre 3 y $5 \mathrm{~mm}$ de lado, que sumaron un total de $18,9 \mathrm{ml}$.
A partir de este material analizado, en primer lugar, se discutirán los resultados a nivel inter-conjunto contrastando los datos polínicos con los datos antracológicos, lo que nos permitirá retomar la discusión acerca de las estrategias de recolección implementadas por los grupos cazadores-recolectores (Marcos \& Ortega 2011) y observar posibles cambios en el uso de los recursos leñosos a lo largo del Holoceno medio y tardío. Esto se realizara a partir de la comparación de los conjuntos antracológicos obtenidos en el sector 1 y fechados en, aproximadamente, 3000 años cal AP (sondeos 1, 2 y 2/B) y aquellos fechados en 1.000 cal años AP (sector LN-E). En segundo lugar, se discutirán los resultados a nivel intra-conjunto, considerando los datos obtenidos por nivel carbonoso, en aquellos sondeos que presentaron una mayor potencia de material (sondeos 2, 2/B y LN-E). Estos resultados nos permitirán retomar la discusión acerca de cuestiones vinculadas con el inicio y mantenimiento del fogón (Ortega \& Marconetto 2009; Marcos \& Ortega 2011).

\section{RESULTADOS}

Análisis polínico, sedimentológico y estratigráfico

El análisis de agrupamiento dividió la secuencia polínica en cuatro zonas (1 a 4), y en dos sub-zonas (2a y 2b). La concentración polínica fue muy variable, de las 45 muestras analizadas 14 presentaron muy baja concentración (muestras 3043 entre 145 a $215 \mathrm{~cm}$ ) y no fueron utilizadas en el análisis (Fig. 3).

Las asociaciones polínicas de la zona 1 (220-215 cm, 6.900-6.700 cal años AP) están caracterizadas por tipos psammófitos (10-20\%), Poaceae (40-80\%) y halófitos como Chenopodiaceae (45\%). Entre los arbustos codominan Nassauvia (10\%) y Ephedra (15-25\%). Además se presentan tipos polínicos herbáceos $(20 \%)$ y de larga distancia como Nothofagus (10\%). La riqueza palinológica fue baja con 5 tipos polínicos. Los sedimentos consisten en partículas limo arenosas con concreciones salinas y libre de eventos pedogenéticos; la materia orgánica y los carbonatos son escasos con valores de 3 y 1,3\% respectivamente. 


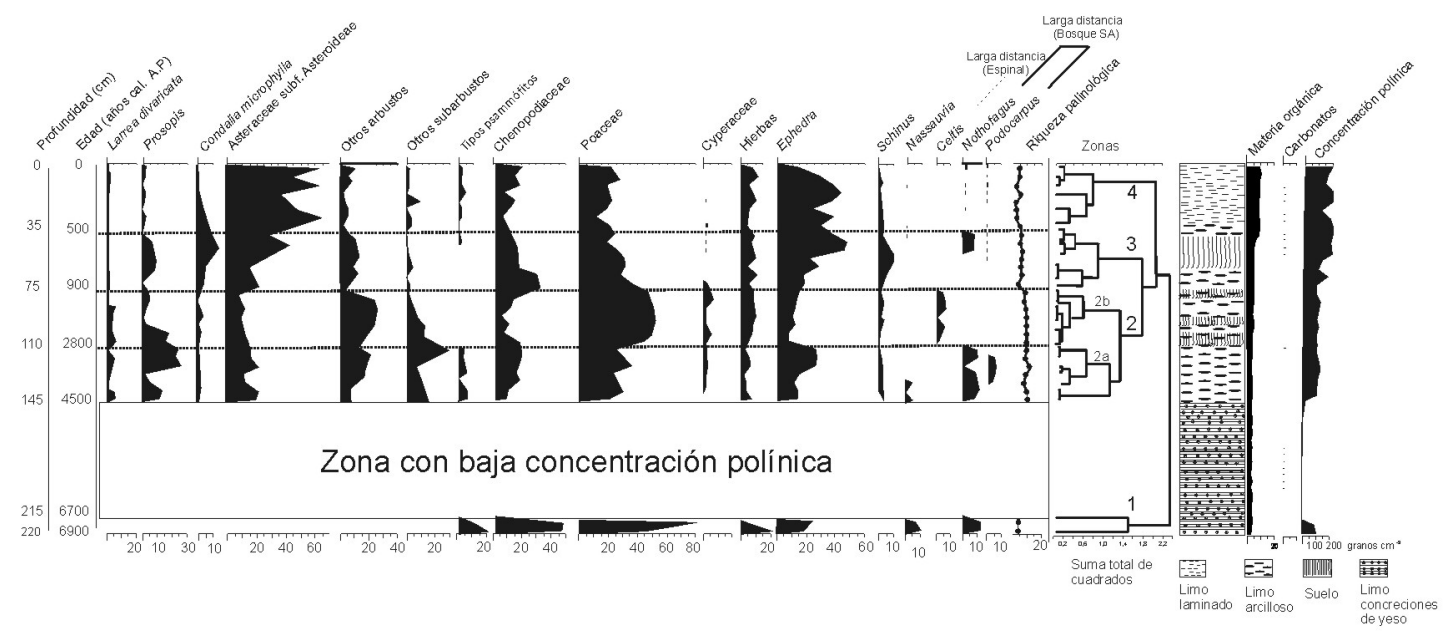

Fig. 3 Diagrama polínico (\%) de la secuencia BQ, riqueza palinológica y zonas polínicas.

Entre los 215 y $145 \mathrm{~cm}$ de profundidad (6.700-4.500 cal años AP) la secuencia presenta una zona con escasa concentración de granos de polen, lo cual no permitió la caracterización polínica. Sedimentológicamente, está representado por partículas limosas con abundantes cristales de yeso que aumentan su tamaño entre los 195 y $215 \mathrm{~cm}$. Los valores de materia orgánica y de los carbonatos son de 3,7 y $2 \%$ respectivamente.

La zona 2 (145-75 cm) se dividió en dos subzonas.

En la sub-zona $2 a \quad(145-110 \mathrm{~cm}$, 4.500-2.800 cal años $\boldsymbol{A P )}$ es relevante la presencia de arbustos de Monte como Prosopis (2-25\%), Asteraceae subf. Asteroideae (10-30\%), Ephedra (15-25\%), otros arbustos y subarbustos (20 y 25\%, respectivamente). Larrea divaricata (5$10 \%)$, Condalia (2-5\%), Schinus (3\%) y Nassauvia (5\%) aunque con bajos porcentajes representan tipos polínicos importantes. En relación a la zona 1 decrecen los valores de los tipos psammófitos y Chenopodiaceae (10-20\%). Las hierbas presentes alcanzan valores entre 5 y $7 \%$ y Poaceae (20$35 \%)$. Los tipos polínicos de larga distancia como Nothofagus y Podocarpus presentan valores de $7-10 \%$ y $2-5 \%$ respectivamente. La riqueza palinológica (8-12 tipos polínicos) aumenta en relación a la zona anterior. Los sedimentos son limo-arcillosos sin cristales de yeso, los valores de materia orgánica son $3,9 \%$ y los carbonatos son $3,6 \%$.
La sub-zona $2 b(110-75 \mathrm{~cm}, 2.800-$ 900 cal años $\boldsymbol{A P})$ está dominada por altos valores de Poaceae (50\%) y otros arbustos (1525\%). Otros arbustos importantes son Larrea divaricata, Prosopis, Condalia y Asteraceae subf. Asteroideae con valores entre 5 y 15\%. Además, se observa un incremento de los porcentajes de arbustos del Espinal (Schinus y Celtis 5-10\%), la ausencia de taxones de larga distancia y una marcada disminución en los porcentajes de Ephedra (10-15\%) y Chenopodiaceae (5-15\%) excepto en una muestra (25\%). El estrato herbáceo/ graminoso está representado por Cyperaceae (1$5 \%$ ) y las hierbas (10\%). La riqueza palinológica es de 8-10 tipos polínicos, los sedimentos son limoarcilloso y presenta sucesivos horizontes A de poco desarrollo. El contenido de materia orgánica es de $5 \%$ y el de carbonatos $1,6 \%$.

La asociación polínica de la zona 3 (7535 cm, 900-500 cal años AP) está dominado por altos valores de Chenopodiaceae (20-50\%), Ephedra (20-50\%) y Asteraceae subf. Asteroideae (30-45\%). Los tipos polínicos herbáceos oscilan entre el 5 y $10 \%$ mientras que los otros arbustos y subarbustos decrecen respecto a la sub-zona $2 b$. Larrea divaricata (1\%) y Prosopis (5-10\%) aunque con bajos porcentajes, representan tipos polínicos importantes de la vegetación de Monte. Se observa un incremento de Condalia microphylla y Schinus (5-10\%) respecto a la zona anterior. Los tipos polínicos de larga distancia, Nothofagus y Podocarpus, muestran valores de $10 \%$ y $1 \%$ 
respectivamente. La riqueza palinológica decrece en relación a la zona anterior con 6-9 tipos polínicos. Esta zona presenta el mayor desarrollo de suelo con sedimentos limo-arcilloso, además un aumento en los valores de materia orgánica (7\%) $y$ un leve crecimiento en los valores de carbonatos (5\%).

Por último, la zona $4(35-0 \mathrm{~cm}, 500$ cal años AP) está caracterizada principalmente por altos valores de Asteraceae subf. Asteroideae (65\%), Ephedra (10-45\%) y los bajos valores de Chenopodiaceae (10-25\%) y Poaceae (20\%) respecto a la zona 3. Larrea divaricata y Prosopis presentan muy bajos valores $(<5 \%)$. Los arbustos y subarbustos presentan valores entre 1-10\% y los tipos psammófitos $2-5 \%$. Los taxones de larga distancia están representados por Nothofagus y Podocarpus (1\%). La riqueza palinológica es baja (5-8 tipos polínicos). Esta zona presenta los más altos valores de materia orgánica (10\%) mientras que los carbonatos oscilan entre 1 y $5 \%$. Los sedimentos corresponden a limos laminados correspondientes a depósitos de laguna.

\section{Análisis antracológicos}

En la Tabla 2 se muestran los resultados obtenidos en cada sondeo, detallando los fragmentos analizados y el volumen de cada género identificado, en valores absolutos y porcentajes.

De acuerdo al análisis inter-sitio se registra el predominio de unos pocos taxones, en relación al resto del conjunto. En el caso del Se. 1, cuyos sondeos (1, 2 y 2 /B) fueron fechados en un rango de 3110 a 3224 años cal AP, se observa una alta frecuencia de Condalia sp. seguida de Prosopis sp. (Fig. 4), al considerar los resultados de ese sector como un todo. Sin embargo, al observar los conjuntos carbonosos por separado, si bien continúa destacándose un taxón por sobre el resto del conjunto, existen diferencias en relación a cuál es el taxón que predomina. En el sondeo 1 se observa una alta frecuencia de Prosopis sp., seguida de Bougainvillea sp.; en el sondeo 2 predomina también Prosopis sp., pero seguido de Condalia sp. y Schinus sp.; y en el sondeo 2/B se destaca una altísima frecuencia de Condalia sp., seguida de Atriplex sp. Si bien estos resultados muestran que Condalia sp. fue utilizada en abundancia como combustible en este sector, la frecuencia destacada de Condalia sp. presente en el sondeo 2/B puede llegar a enmascarar su uso más moderado (o el predominio de otros taxones) en los otros sondeos del mismo sector (Fig. 4).

El conjunto antracológico recuperado en La Noria-Este, fechado en aproximadamente 929 años cal AP presentó importantes diferencias respecto al Sector 1 . Se observa en LN-E una destacada frecuencia de Chuquiraga sp., seguida de Geoffroea sp. y Schinus sp. (Fig. 4). Resulta significativo, que en este conjunto se registraron dos taxones (I y II) cuyos caracteres diagnósticos no coinciden con ninguno de los géneros incluidos en la muestra de referencia. Esto podría estar indicando la presencia de dos especímenes leñosos presentes durante los momentos en que se formó el conjunto y que están ausentes en la actualidad, o dos taxones cuya falta de ubicuidad en la actualidad explicaría su omisión dentro de la colección de referencia.

Por último, se consideraron los resultados obtenidos por nivel en aquellos sondeos constituidos por dos estratos de carbón: sondeos 2 y 2/B del Sector 1, y el sondeo LN-E (Fig.5). En los resultados de Se. 1 se observan diferencias tanto entre los niveles de cada conjunto, como entre

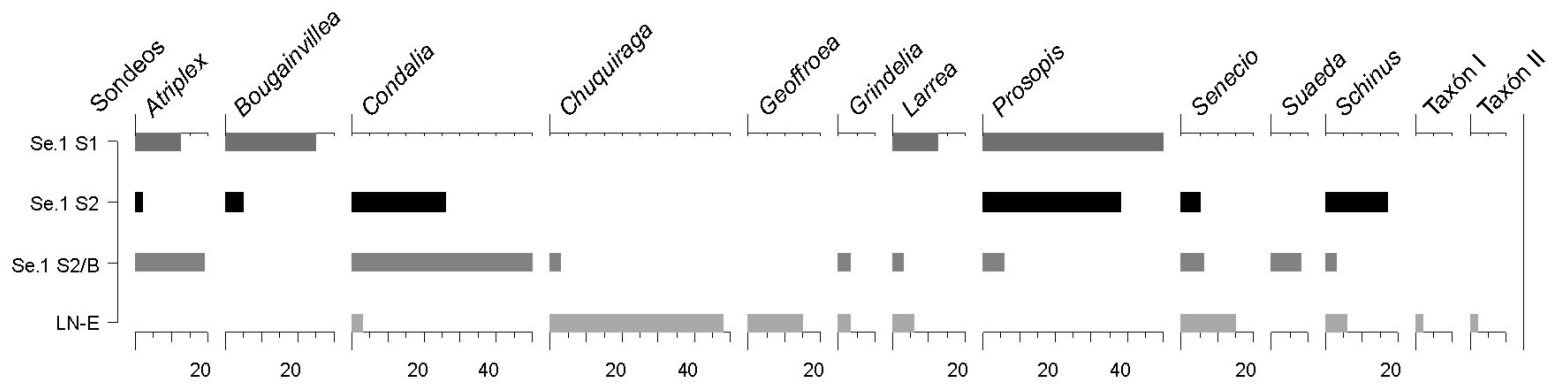

Fig.4. Distribución de los resultados de análisis antracológicos obtenidos en cada sondeo. 


\begin{tabular}{|c|c|c|c|c|c|c|c|c|c|c|c|c|c|c|c|}
\hline & $\begin{array}{l}3_{0}^{\circ} \\
0^{\circ}\end{array}$ & 0 & 0 & م & $\hat{n}$ & $\underset{\sim}{0}$ & $m$ & 0 & 0 & $\stackrel{\simeq}{\sim}$ & 0 & $\stackrel{0}{-1}$ & $m$ & $m$ & 8 \\
\hline & $\begin{array}{l}0 \\
0 \\
0\end{array}$ & 0 & 0 & $\neg$ & 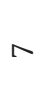 & $m$ & $\stackrel{\circ}{\circ}$ & $\stackrel{N}{\sim}$ & 0 & $\stackrel{N}{N}$ & 0 & $m$ & $\stackrel{1}{0}$ & $\stackrel{2}{0}$ & $\begin{array}{l}\sigma \\
\infty \\
\sim\end{array}$ \\
\hline 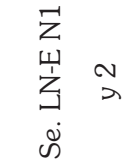 & 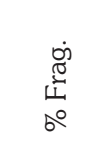 & 0 & 0 & $m$ & $\stackrel{\infty}{+}$ & $\stackrel{2}{\sim}$ & $m$ & 0 & 0 & $\stackrel{2}{\sim}$ & 0 & 0 & $\sim$ & $\sim$ & 움 \\
\hline & 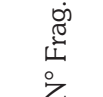 & 0 & 0 & $\sim$ & ి) & $a$ & $N$ & $\sigma$ & 0 & $a$ & 0 & $\sigma$ & $\neg$ & $\neg$ & ָ \\
\hline & $\overrightarrow{0}$ & 윽 & 0 & ชె & $m$ & 0 & $m$ & $m$ & $\sigma$ & $\llcorner 0$ & $\llcorner 0$ & 0 & 0 & 0 & 음 \\
\hline & $\vec{\rho} 0$ & $\sigma$ & 0 & $\stackrel{\llcorner}{\sim}$ & - & 0 & $r$ & 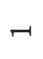 & ن & $N$ & $N$ & $\stackrel{\llcorner}{N}$ & 0 & 0 & 우 \\
\hline $\begin{array}{lll}\dot{v} & \vec{Z} & \\
\vec{r} & \infty & \sim\end{array}$ & 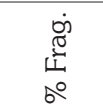 & 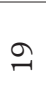 & 0 & 요 & $m$ & 0 & $m$ & $m$ & 0 & 0 & $\infty$ & $m$ & 0 & 0 & $\stackrel{8}{\circ}$ \\
\hline & 之 & 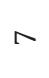 & 0 & $\stackrel{\infty}{\sim}$ & $\neg$ & 0 & $\neg$ & $\neg$ & $\sim$ & $\sim$ & $m$ & - & 0 & 0 & ల్ల \\
\hline & $\begin{array}{l}\overrightarrow{0} \\
0^{\circ}\end{array}$ & $m$ & $\infty$ & $\vec{N}$ & 0 & 0 & 0 & $m$ & के & $\infty$ & 0 & $\stackrel{\infty}{\sim}$ & 0 & 0 & 욱 \\
\hline & $\vec{\rho} \quad u$ & - & $\stackrel{\llcorner}{N}$ & น & 0 & 0 & 0 & -1 & $\stackrel{\sim}{\sim}$ & $\stackrel{\llcorner}{\mathrm{N}}$ & 0 & مْ & ○ & 0 & $\vec{m}$ \\
\hline $\begin{array}{ll}N & \sim \\
\omega & \lambda \\
\vec{\omega} & \vec{z} \\
\omega & z\end{array}$ & 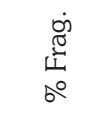 & $\sim$ & مL & $\stackrel{\sim}{\sim}$ & 0 & 0 & 0 & $\sim$ & $\stackrel{\infty}{\infty}$ & 10 & 0 & . & 0 & 0 & 음 \\
\hline & 之 & $\neg$ & $N$ & 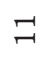 & 0 & 0 & 0 & $n$ & $\stackrel{0}{-1}$ & $\sim$ & 0 & $\Lambda$ & 0 & 0 & $\stackrel{\sim}{\forall}$ \\
\hline & $\begin{array}{l}\overrightarrow{0} \\
0^{\circ}\end{array}$ & $\stackrel{\sim}{\sim}$ & $\stackrel{\llcorner}{N}$ & 0 & 0 & 0 & 0 & $\stackrel{\sim}{\sim}$ & 유 & 0 & 0 & 0 & 0 & 0 & 8 \\
\hline & $\vec{\rho} 0$ & $\stackrel{\text { L }}{0}$ & - & 0 & 0 & 0 & 0 & $\stackrel{\text { L }}{0}$ & $\sim$ & 0 & 0 & 0 & 0 & 0 & $\sigma$ \\
\hline \multirow[t]{3}{*}{$\begin{array}{l}\vec{\omega} \\
\overrightarrow{\dot{m}} \\
\dot{\omega}\end{array}$} & 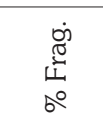 & $\stackrel{\llcorner}{\sim}$ & $\stackrel{\llcorner}{N}$ & 0 & 0 & 0 & 0 & 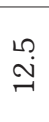 & 옹 & 0 & 0 & 0 & 0 & 0 & 옥 \\
\hline & 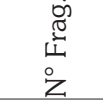 & $\sim$ & $\sigma$ & 0 & 0 & 0 & 0 & $\sim$ & $\infty$ & 0 & 0 & 0 & 0 & 0 & $\underset{\sim}{0}$ \\
\hline & 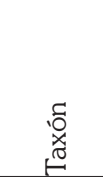 & 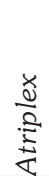 & 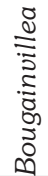 & $\begin{array}{l}\frac{0}{0} \\
\frac{0}{0} \\
\overline{0} \\
0\end{array}$ & 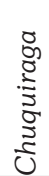 & 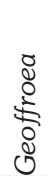 & 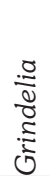 & 竎 & $\begin{array}{l}: 0 \\
\overline{0} \\
0 \\
0 \\
0 \\
0\end{array}$ & 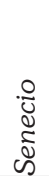 & $\begin{array}{l}\frac{0}{8} \\
8 \\
\frac{8}{5} \\
\omega\end{array}$ & 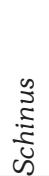 & 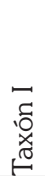 & 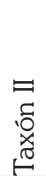 & 㺃 \\
\hline
\end{tabular}




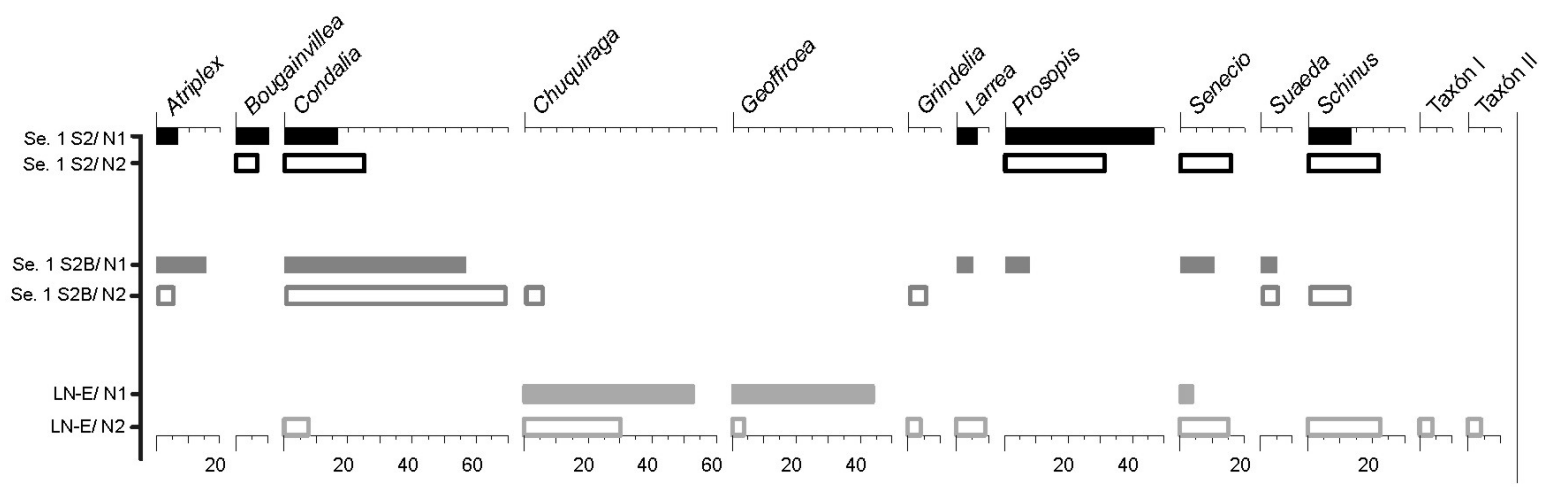

Fig.5. Distribución de los resultados de análisis antracológicos obtenidos por nivel.

los niveles interconjunto. El sondeo 2 presenta una alta frecuencia de Prosopis sp. seguido de Condalia sp., tanto en el nivel superior (N1) como en el nivel inferior (N2). Sin embargo, el N2 presenta asimismo una elevada frecuencia de Schinus sp. y de Senecio sp., este último ausente en el N1. Luego, en el sondeo $2 / \mathrm{B}$ se registra una muy alta frecuencia de Condalia sp. en ambos niveles, seguida de Atriplex sp., en el N1 y de Schinus sp. en el N2. Por último, el sondeo LN-E se destaca notablemente de los anteriores, no sólo por las diferencias taxonómicas que presenta, sino también por las diferencias en riqueza taxonómica que presenta cada nivel. La predominancia de Chuquiraga sp., prácticamente ausente en los sondeos del Se. 1, se registra en ambos niveles, seguida de Geoffroea sp., en el N1, y de Schinus sp., en el N2. En cuanto a la riqueza taxonómica, resulta notoria la diferencia de diversidad que se observa entre el N1 y el N2, registrándose la presencia de 3 taxones en el primero y 9 en el segundo. De este modo, el sondeo realizado en el sector La Noria-Este se diferencia de aquellos del sector 1 , los cuales presentan una diversidad florística más constante (entre 5 y 6 taxones en cada nivel) (Fig. 5).

\section{Registros polínicos y antracológicos}

La contrastación de los registros polínicos y antracológicos se realizó para dos períodos particulares 3.000 años cal AP y 1.000 años cal $\mathrm{AP}$ (Fig. 6A y B). Los resultados indican a los 3.000 años cal AP altos porcentajes de Prosopis sp. y Chenopodiaceae tanto en el registro polínico como antracológico, mientras que sólo este último

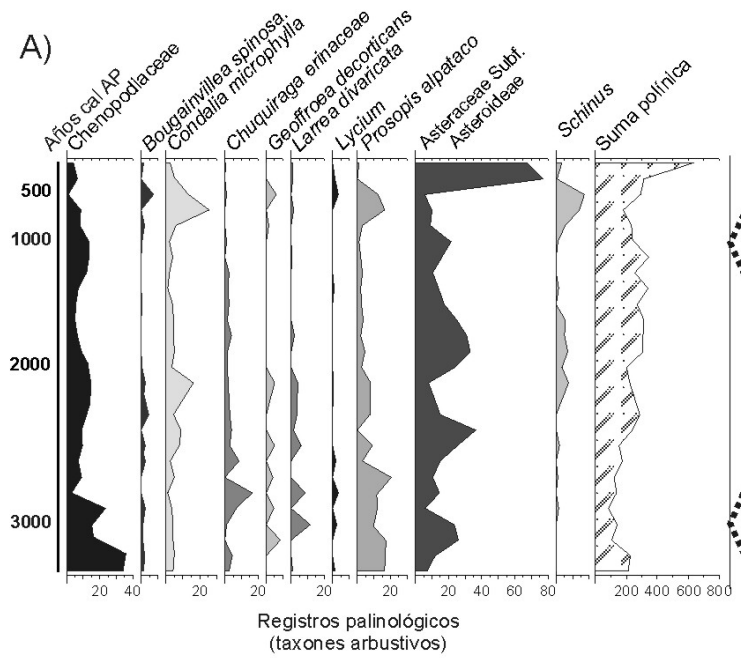

B) Registros antracológicos

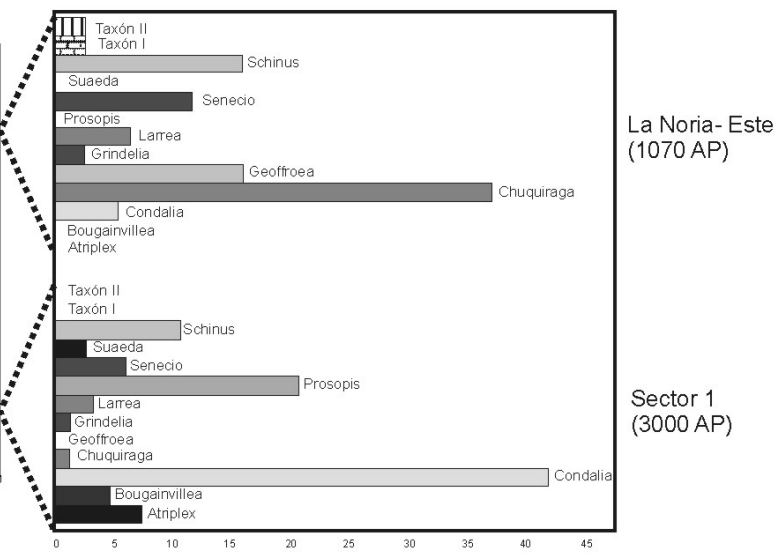

Fig.6. Principales taxones arbustivos polínicos (A) y antracológicos (B) de Bajo de la Quinta. 
señaló altos valores de Condalia sp. y moderados valores de Schinus sp.

Ambos registros para los 1.000 años cal AP muestran altos valores de Asteraceae subf. Asteroideae (Chuquiraga sp. y Senecio sp.) sin embargo sólo el registro antracológico exhibe altos valores de Schinus sp.y Geoffroea sp.y moderados valores de Condalia sp.y Larrea sp..

Estos resultados permitieron inferir el escenario paleoambiental en el cual los cazadoresrecolectores del Holoceno medio y tardío se movieron búsqueda de recursos leñosos para sus fogones. La diversidad florística que reflejan los taxones polínicos arbustivos de la secuencia brinda información sobre la oferta ambiental de leños potencialmente explotables por estos grupos.

\section{DISCUSIÓN}

Reconstrucción paleoambiental de Bajo de la Quinta

La reconstrucción paleoambiental de Bajo de la Quinta ha sido posible en base a la comparación con los datos polínicos actuales (Marcos \& Mancini 2012). Durante el comienzo del Holoceno medio (6.900-6.700 años cal AP) los conjuntos polínicos indican la presencia de vegetación psammófita (Chenopodiaceae y Poaceae) y xerófita, bajo condiciones más áridas que las actuales y la expansión hacia el este de la formación Estepa Patagónica, inferidos por altos valores de Ephedra y valores moderados de Nassauvia. Las proporciones de los tipos polínicos de larga distancia, tales como Nothofagus sugieren la influencia de los vientos del oeste durante este período. Los sedimentos limo-arenosos y las concreciones de yeso indican procesos fluviales $y$ una mayor dinámica sedimentaria, con transporte de sedimento desde los afluentes hacia la costa antes de la formación de la laguna.

Entre los 6.700 y 4.500 años cal AP se presenta una zona con baja preservación polínica, con características estratigráficas similares a la zona 1 y numerosas concreciones de yeso, que indicarían sucesivos ciclos de humedad-sequedad en el ambiente sedimentario. La falta de preservación polínica en este período podría deberse a las condiciones de oxidación en los eventos de desecación del cuerpo de agua.

Entre los 4.500 y 2.800 años cal AP predomina una estepa arbustiva-graminosa típica del Monte, representada por Larrea divaricata, Prosopis, Condalia, entre otros arbustos y subarbustos. Se infieren condiciones áridas en relación a lo actual reflejadas por los altos valores de Ephedra y la presencia de Nassauvia. La influencia de los vientos del oeste es indicada por los altos valores de Nothofagus y Podocarpus durante este período. La estratigrafía de este sector evidencia el desarrollo de suelos con horizontes A de suelo de poco desarrollo, probablemente formados durante los períodos de desecación del cuerpo de agua.

La secuencia polínica refleja durante el Holoceno tardío un cambio en las condiciones ambientales (2.800-900 años cal AP) evidenciado por la influencia de los taxa del Espinal como Schinus y Celtis, la disminución de Ephedra y la ausencia de Nassauvia. Además es notable la disminución de Chenopodiaceae respecto a la zona anterior y de tipos polínicos de larga distancia como Nothofagus y Podocarpus. Esto coincide con lo postulado por Schäbitz (1994) y Schäbitz \& Liebricht (1998) sobre un cambio hacia condiciones climáticas semiáridas con frecuentes eventos de precipitaciones, alrededor de 3.000 años cal AP en el noreste de la Patagonia, relacionado con el debilitamiento de los vientos del oeste y la influencia de las masas de aire húmedo del Atlántico que penetran en el continente. Además, condiciones ambientales más estables propiciaron un mayor desarrollo de la estepa arbustiva del Monte, lo cual es evidenciado por la presencia de sedimentos limosos a limo-arcillosos (Marcos et al. 2011).

Entre los 900 y los 500 años cal AP el registro polínico refleja una disminución en la cantidad de gramíneas (Poaceae y Cyperaceae), altos valores de especies leñosas (Prosopis, Condalia, Schinus entre otros) y un aumento en Chenopodiaceae y Ephedra. Una estepa arbustiva xerofítica similar a la actual (Marcos \& Mancini 2012) asociada a vegetación halófita (Chenopodiaceae) comienza a formarse en este período y se relaciona con la formación de una laguna incipiente en Bajo de la Quinta.

La vegetación arbustiva actual del área está representada en los últimos 500 años cal AP con altos valores de Asteraceae subf. Asteroideae 
vinculado posiblemente a vegetación arbustiva edáfica de los alrededores de la laguna (Marcos \& Mancini 2012).

Uso de los recursos leñosos por los grupos cazadores-recolectores: integración de datos polínicos y antracológicos

Los análisis antracológicos permitieron identificar qué tipos leñosos fueron los que utilizaron regularmente los cazadores-recolectores para el encendido y mantenimiento de sus fuegos. Retomando el supuesto, que los taxones que hayan sido más utilizados tienen más probabilidad de dejar un porcentaje mayor de residuos carbonosos (Piqué i Huerta 1999), se puede considerar que los taxones cuyos volúmenes predominan en los conjuntos analizados han sido los más frecuentemente utilizados por estos grupos. En cazadores recolectores, la explotación de recursos leñosos se da en un rango que va desde la recolección azarosa hasta la presión sobre un taxón en particular. Si bien la selección de leños está condicionada por la oferta ambiental, son las variables culturales (capacidades técnicas de los grupos y aspectos socio-económicos y simbólicos) las que determinan en última instancia, las estrategias de recolección de leña para el encendido de los fuegos (Piqué i Huerta 1999; Marconetto 2008; Ortega \& Marconetto 2009).

No obstante la homogeneidad que presenta la vegetación del Monte, las asociaciones entre las variables polínicas en los últimos 6900 años cal $\mathrm{AP}$, han registrado fluctuaciones en la diversidad y la distribución de la vegetación en respuesta a forzantes climáticos. De acuerdo a los resultados de este trabajo se puede inferir que la modificación de la oferta ambiental durante el Holoceno mediotardío tuvo incidencia en las formas de recolección de combustible por las que optaron los grupos cazadores recolectores.

En particular a los 3.000 años cal AP, se ha registrado un cambio importante en las condiciones ambientales en el noreste de Patagonia (Marcos et al. 2011, 2012; Schäbitz 1994; Schäbitz \& Liebricht 1998). El registro polínico y antracológico indican para este período altos porcentajes de Prosopis sp. y Chenopodiaceae, sin embargo, sólo el registro antracológico señala altas frecuencias de Condalia sp. y moderados valores de Schinus sp. Las condiciones ambientales reinantes durante este período habrían favorecido la abundancia de taxones tales como Prosopis sp y Chenopodiaceae, como indicaron los análisis palinológicos. Dada la alta frecuencia de Prosopis sp. y Atriplex sp. (Chenopodiaceae) en el registro antracológico se infirió que la oferta local de leñosas habría condicionado la estrategia de recolección de combustible. La presencia de Chenopodiaceae, en particular, en el registro polínico está asociada a la abundante vegetación halófita que se establece en los bordes de laguna lo cual podría haber favorecido su recolección por los grupos que habitaron el área. Por otro lado, las altas frecuencias de Condalia sp. y de Schinus sp. en el registro antracológico podrían reflejar una mayor presión de selección sobre estas especies leñosas, determinada por pautas culturales (Marcos \& Ortega, 2011).

En el presente trabajo, al discriminar los resultados de análisis antracológicos por sondeo se observó que en dos de los ellos (sondeos 1 y 2) las frecuencias de Prosopis sp. se incrementaban sobre del resto de los taxones. De acuerdo a estos datos, la abundancia de Prosopis sp. el ambiente durante este período, podría haber favorecido la recolección azarosa del mismo por los grupos humanos. Sin embargo, las altas frecuencias de otros leños que acompañan a Prosopis sp. en ambos conjuntos (Grindelia sp., Condalia sp., Schinus sp.) escasez en el ambiente circundante contrasta con el registro antracológico, y los altos valores de Condalia sp. en el Sector 1, hacen desestimar esta posibilidad. En este sentido, se puede considerar que la selección de determinadas especies leñosas fue la estrategia favorecida por los grupos que habitaron en Bajo de la Quinta hacia los 3.000 años cal AP.

El desarrollo de una estepa arbustiva de Monte asociada a condiciones semiáridas se establece a fines del Holoceno tardío. En este período es notorio la abundancia de tipos leñosos como Schinus sp. y Condalia microphylla. Si bien el cambio en las condiciones ambientales (árido a semiárido) pudieron afectar el uso de los recursos combustibles como se observa en el registro antracológico más tardío (mayor frecuencia de Chuquiraga sp. y Geoffroea sp.) las estrategias de recolección se mantuvieron constantes: se observa 
una mayor presión sobre un taxón en particular, Chuquiraga sp., cuya alta frecuencia de uso contrasta con su escasez ambiental, registrada a través del polen (Fig.6).

Se observa, entonces, que los cazadores recolectores que habitaron el área de Bajo de la Quinta hace 3.000 y 1.000 años cal AP favorecieron una estrategia de selección de determinadas especies para el encendido de sus fuegos. Las causas que habrian llevado a estos grupos a optar por una estrategia de este tipo, podrían deberse a las calidades de los diferentes leños como iniciadores o como alimentadores del fogón. El uso de Atriplex sp. para iniciar el fogón y de Prosopis sp. para alimentarlo ya ha sido planteado por otros investigadores (Marconetto 2005). Como se ha planteado en trabajos previos (Ortega \& Marconetto 2009, Marcos \& Ortega 2011), especies leñosas como Atriplex sp. y Suaeda sp. podrían haber sido favorecidas debido a su calidad como iniciadores del fuego (la presencia de inclusiones, como haces de floema y cristales, en sus tejido favorecen su rápida combustión) y Prosopis sp. y Condalia sp., las cuales presentan óptimas características como combustible, podrían haber sido utilizadas para la alimentación del fogón. Como se observó en el análisis intra- conjunto de los sondeos 2 y 2/B (Sector 1), se registró en el nivel 2 de ambos sondeos la presencia de taxones como Atriplex sp., Suaeda sp. y Bougainvillea sp., posiblemente utilizadas como iniciadores. Tanto en los niveles inferiores (nivel 2) como en los superiores (nivel 1) de ambos sondeos predominan taxones como Condalia sp. y Prosopis sp., situación que puede estar respondiendo a las actividades relacionadas con el mantenimiento y la alimentación del fogón. El conjunto antracológico recuperado en el Sector LN-E parece reflejar una historia diferente, aunque vinculada a las mismas actividades de inicio y mantenimiento del fogón. La presencia, en el nivel 2, de 9 taxones diferentes, 8 de los cuales generaron menor residuo (como lo demuestra su baja frecuencia en el registro), podría estar vinculándose al testeo de diferentes especies a ser utilizadas como iniciadores del fuego. El notable aumento en la frecuencia de dos de estos taxones, Chuquiraga sp. y Geoffroea sp., hacia el nivel superior, y el uso prácticamente exclusivo que se le da a los mismos hacia el final del episodio, podría vincularse con la selección de estos dos leños como alimentadores del fogón.

Para finalizar, y atendiendo la discusión presentada previamente, no dejamos de tener en cuenta que cuestiones tales como la combustión diferencial de leños, así como factores postdepositacionales que eliminen de manera diferencial a los taxones del registro, pueden estar afectando las frecuencias taxonómicas observadas en cada conjunto (Ortega \& Marconetto 2009). La realización de estudios experimentales con las diferentes leñosas del área aportará datos importantes respecto a la combustión diferencial y proporcionará nueva información acerca de las calidades de las diferentes especies como iniciadores y alimentadores del fogón.

\section{CONCLUSIONES}

Los registros polínicos permitieron reconstruir la historia paleoambiental de Bajo de la Quinta. Dado que la vegetación arbustiva del Monte es bastante homogénea en su fisonomía, las proporciones y las asociaciones encontradas entre los taxones polínicos fósiles, fueron los elementos claves que permitieron detectar cambios en la vegetación y en al ambiente desde el Holoceno medio en la costa norte de Patagonia. Durante el Holoceno medio (6.900 años cal AP), la vegetación estuvo representada por una estepa arbustiva xerófita con grandes parches de suelo desnudo. Este escenario paleoambiental estuvo determinado por condiciones ambientales áridas con una marcada influencia de los vientos del oeste. Sin embargo, durante el Holoceno tardío (3.000 años cal AP) se registra un cambio en las condiciones ambientales de árido a semiárido asociado a un debilitamiento de los vientos del oeste. Una estepa arbustiva típica de Monte se evidencia para este período con gran diversidad de especies leñosas como Prosopis sp., Larrea sp., Schinus sp., Geoffroea sp., entre otras.

La comparación de registros polínicos y antracológicos ha brindado interesantes resultados acerca de la utilización de recursos leñosos como combustible y cómo este uso estuvo condicionado por los factores ambientales y/o culturales durante el Holoceno tardío, en particular a los 3.000 y 1.000 años cal AP. 
Este trabajo resulta un aporte al estudio de las ocupaciones humanas, el uso de los recursos y su relación con los cambios ambientales ocurridos durante el Holoceno medio-tardío.

\section{AGRADECIMIENTOS}

Las autoras agradecen al Dr. Cristian Favier Dubois y la Dra. Florencia Borella directores del proyecto de investigación arqueológica del área de estudio, a la Sra. Irma Stabile (dueña de la estancia La Madreselva) y al encargado del campo (Sr. Bonifacio) por permitirnos el acceso al lugar de trabajo. Nuevamente al Dr. Cristian Favier Dubois por la lectura crítica del manuscrito. A la Dra. Florencia P. Bamonte por sus sugerencias y ayuda en la confección de las figuras. Además, nuestro agradecimiento al revisor del manuscrito, por sus sugerencias y valiosos aportes. Este estudio ha sido desarrollado dentro de los siguientes proyectos: PIP CONICET 112-200801-00756, PIP-CONICET 1265 y EXA 510/10 (UNMDP).

\section{BIBLIOGRAFÍA}

Abraham, E., Del Valle, H. F., Roig, F., Torres, L., Ares, J. O., Coronato, F. \& Godagnone, R. (2009). Overview of the geography of the Monte Desert biome (Argentina). Jounal of Arid Environments, 73,144-153.

Ancibor E., \& Pérez de Micou, C. (1995). Identification of firewood species in the archaeological record of the patagonian steppe. Journal of Etnobiology, 15 (2), 189-200.

Ancibor E., \& Pérez de Micou, C. (2002). Reconocimiento de especies vegetales combustibles en el registro arqueológico de la estepa patagónica. En C. Pérez de Micou (comp.), Plantas y cazadores de la Patagonia (pp. 15-32). Buenos Aires, Argentina: Facultad de Filosofía y Letras (UBA).

Bengtsson, L. \& Enell, M. (1986). Chemical analysis. En Berglund, B. E. John Wiley \& Sons, Chichester (Eds.), Handbook of Holocene Palaeoecology and Palaeohydrology (423-451 pp) England, UK.

Bennet, K. D. \& Willis, K. J. (2001). Pollen. En Smol J. P., Birks H.J.B., Last W. M. (Eds.), Traking Environmental Changes Using Lake Sediments. Terrestrial, Algal and Siliceous Indicators, Kluwer Academic Publishers Dordrecht.

Bianchi, M. M. \& D`Antoni, H. (1986). Depositación del polen actual en los alrededores de Sierra de la Padres (Prov. Buenos Aires). IV Congreso Argentino de Paleontología y Bioestratigrafía, Mendoza.

Borella, F., Favier Dubois, C. M., Lanzelotti, S. \& Cardillo, M. (2004). Proyecto arqueológico en el Golfo San Matías (Río Negro). Primera etapa de las investigaciones. XV Congreso Nacional de Arqueología Argentina, Río Cuarto.

Borella, F., Mariano, C., \& Favier Dubois, C. M. (2007). Procesos tafonómicos en restos humanos de la localidad arqueológica de Bajo de la Quinta, Golfo San Matías (Río Negro), Argentina. En F. Morillo, M. Martinic, A. Prieto \& G. Bahamonde (Eds.), Arqueología de FuegoPatagonia. Levantando piedras, desenterrando huesos... y develando arcanos (pp. 403-410). Punta Arenas, Chile: Ediciones CEQUA.

Bórmida, M. (1964). Arqueología de la costa Nordpatagónica. Trabajos de Prehistoria XIV. Madrid.

Borrero, L. (1989-90). Evolución cultural divergente en la Patagoniaaustral. Anales del Instituto de la Patagonia. Serie Ciencias Sociales, 19, 133-139.

Castro, M. A. (1994). Maderas argentinas de Prosopis. Atlas anatómico. Buenos Aires, Argentina: Presidencia de la Nación, Secretaría General.

Faegri, K. \& J. Iversen. (1989). Texbook of Pollen Analysis. Copenhangen. Faegri, K., Kaland, P. E. \& Krywinski, K. Wiley.

Favier Dubois, C. M. (2009). Valores del efecto reservorio para los últimos 5.000 años obtenidos en concheros de la costa Atlántica Nordpatagónica (Golfo San Matías, Argentina). Magallania, 37(2), 139-147.

Favier Dubois, C. M. \& Borella, F. (2007). Consideraciones acerca de los procesos de formación de concheros en la costa norte del Golfo San Matías. Cazadores Recolectores del Cono Sur, 2, 151-165.

Favier Dubois, C. M., \& Borella, F. (2011). Contrastes en la costa del Golfo: Una aproximación al estudio del uso humano del litoral rionegrino en el pasado. En M. Cardillo \& F. Borella (Eds.) Arqueología de pescadores y marisqueadores en nordpatagonia (pp. 14-41). Buenos Aires, Argentina: Editorial Dunken.

Favier Dubois C.M. \& Scartacini, F.L. (2011). Intensive fishery scenarios on the North Patagonian coast (Río Negro, Argentina) during the Mid-Holocene. Quaternary International, 256, 62-70.

Favier Dubois, C., Borella, F., Manzi, L., Cardillo, M., Lanzellotti, S., Scartascini, F., Mariano, C. \& Borges Vaz, E. (2008). Aproximación regional al registro arqueológico de la costa rionegrina. Arqueología de la costa patagónica. 
En I. Cruz \& S. Caratcoche (Eds.) Perspectivas para la Conservación (pp. 50-68). Río Gallegos, Argentina: Universidad Nacional de la Patagonia Austral.

Favier Dubois, C. M, Borella, F., \& Tykot, R. H. (2009). Explorando tendencias temporales en el uso del espacio y los recursos marinos en el Golfo San Matías (Río Negro). En F. Santiago, M. Salemme, M. Alvarez, E. Piana, M. Vázquez, y M. E. Mansur (Eds.) Arqueología de Patagonia: una mirada desde el último confin (Vol. 2, pp. 985-997). Ushuaia, Argentina: Editorial Utopías.

Favier Dubois, C. M \& Kokot, R. (2011). Changing scenarios in Bajo de la Quinta (San Matías Gulf, Northern Patagonia, Argentina): Impact of geomorphologic processes in subsistence and human use of coastal habitats. Quaternary International, 245(1), 103-110.

Garreaud, R.D., Lopez, P., Minvielles, \& M. Rojas, M. (2013). Large Scale Control on the Patagonia Climate. Journal of Climate 26, 215-236.

Gray, J. (1965). Palynological techniques. En Kummel, B \& Raup, D. (Eds.), Handbook of Palontological Techniques, (pp. 471-587). San Francisco: W.H. Freeman.

Grimm, E. (2004). Tilia Software 2.0.2, Illinois State Museum. Research and Collection Center. Springfield, Illinois.

IAWA Committee. (1964). Multilingual glossary of terms used in wood anatomy. Konkordia, Switzerland: International Association of Wood Anatomists. Wheeler, E. A., Baas, P., \& P. E. Grason (Eds.). List of microscopic features for hardwood identification (IAWA Bulletin). Leiden, The Netherlands: Rijksherbarium.

IAWA Committe. (1989). IAWA list of microscopic features for hardwood identification. International Association of wood anatomists, Bulletin n.s. 10, 219-332.

Heiri, O., Lotter, A. \& Lemcke, G. (2001). Loss on ignition as a method for estimating organic and carbonate content in sediments: reproducibility and comparability of results. Journal of Paleolimnology, 25, 101-110.

Kokot, R. R., Codignotto, J. O. \& Elissondo, M. (2004). Vulnerabilidad al ascenso del nivel del mar en la costa de la provincia de Río Negro. Revista de la Asociación Geológica Argentina, 59(3), 477-487.

Labraga, J.C. \& Villalba, R. (2009). Climate in the Monte Desert: Past trends, present conditions, and future projections. Journal of Arid Environments, 73, 154163.

Mancini, M.V. (1998). Vegetation changes during the Holocene in Extra-Andean Patagonia, Santa Cruz Province, Argentina. Palaeogeography, Palaeoclimatology and Palaeoecology 138(1-4), 207-219.
Mancini, M.V. (2002). Vegetation and climate during the Holocene in Southwest Patagonia, Argentina. Review of Palaeobotany and Palinology, 122, 101-115.

Marconetto, M. B. (2002). Análisis de los vestigios de combustión de los sitios Alero Don Santiago y Campo Moncada. En C. Pérez de Micou (Ed.) Plantas y cazadores en Patagonia (pp. 33-53). Buenos Aires, Argentina: Facultad de Filosofía y Letras (UBA).

Marconetto, M. B. (2005). Recursos forestales y el proceso de diferenciación social en tiempos prehispánicos en el valle de Ambato, Catamarca. Tesis Doctoral, Universidad Nacional de La Plata.

Marconetto, M. B. (2008). Recursos forestales y el proceso de diferenciación social en tiempos Prehispánicos en el Valle de Ambato, Catamarca, Argentina. En A. D. Izeta (Ed.) South American Archaeology Series (No. 3). Oxford, England: BAR International Series 1785.

Marcos, M. A. \& Ortega, F. V. (2011). Registros polínicos y antracológicos: su relación con las ocupaciones humanas. En: A. F. Zangrando, R. Barberena, A. Gil, G. Neme, M. Giardina, L. Luna, C. Otaola, S. Paulides, L. Salgán \& A. Tivoli (Eds.). Tendencias teóricometodológicas y casos de estudio en la arqueología de la Patagonia (pp. 119-127). Mendoza: Editoriales Sociedad Argentina de Antropología, Instituto Nacional de Antropología \& Pensamiento Latinoamericano el Museo de Historia Natural de San Rafael.

Marcos, M. A., Favier Dubois, C. M. \& Mancini, M. V. (2011). Aportes de los estudios palinológicos a la arqueología de la costa rionegrina: el caso del bajo de la quinta. En Cardillo, M. \& Botella, F Arqueología de pescadores y marisqueadores en nordpatagonia (pp. 129-144). Buenos Aires: Editorial Dunken,

Marcos, M. A. \& Mancini, M. V. 2012. Modern pollen and vegetation relationships in Northeastern Patagonia (Golfo San Matías, Río Negro). Review of Paleobotany and Palynology, 171, 19-26.

Marcos, M. A., Mancini, M. V. \& Favier Dubois, C. M. (2012). Middle-Late Holocene environmental changes in Bajo de la Quinta, NE Patagonia, inferred by palynological records and their relation to human occupation. The Holocene, 22(11), 1271-1281.

Manzi, L. M., Favier Dubois, C. M. \& Borella, F. (2009). Identificación de agentes perturbadores y estrategias tendientes a la conservación del patrimonio arqueológico en la costa del Golfo San Matías, Pcia. de Río Negro. Revista Intersecciones en Antropología, 10, 3-16.

McCormac, F. G., Hogg, A. G., Blackwell, P. G., Buck, C. 
E., Higham, T. F. G.\& Reimer, P. J. (2004). SHCal04 Southern Hemisphere Calibration 0 - 1000 cal BP. Radiocarbon, 46, 1087-1092.

Morello, J. (1958) La Provincia Fitogeográfica del Monte. Opera Lill 2, 1-155.

Ortega, F. V., \& Marconetto, M. B. (2009). Una discusión "encendida". Primeros resultados de los análisis de vestigios de combustión en concheros de la Costa Norpatagónica (Río Negro). En F. Santiago, M. Salemme, M. Alvarez, E. Piana, M. Vázquez, y M. E. Mansur (Eds.) Arqueología de Patagonia: una mirada desde el último confín (pp. 1141-1148). Ushuaia, Argentina: Editorial Utopías.

Ortega, F. V., \& Marconetto, M. B. (2011). La explotación de recursos combustibles: su uso y representación en la costa rionegrina a través de los restos antracológicos. En M. Cardillo \& F. Borella (Eds.) Arqueología de pescadores y marisqueadores en nordpatagonia (pp. 112-128). Buenos Aires, Argentina: Editorial Dunken.

Piqué i Huerta, R. (1999). Producción y uso de combustible vegetal: una evaluación arqueológica. Treballs d' Etnoarqueologia, 3. Madrid, España: Consejo Superior de Investigaciones Científicas y Universidad Autónoma de Barcelona.

Reimer P. J., Baillie, M. G. L., Bard, E., Bayliss, A., Beck, J. W., Bertrand, C. J. H., Blackwell, P. G., Buck, C. E., Burr, G. S., Cutler, K. B., Damon, P. E., Edwards, R. L., Fairbanks, R. G., Friedrich, M., Guilderson, T. P., Hogg, A. G., Hughen, K. A., Kromer, B.,. McCormac, F. G, Manning, S. W., Ramsey, C. B., Reimer, R. W., Remmele, S., Outhon, J. R.S, Stuiver, M., Talamo, S., Taylor, F. W., Van Der Plicht, J. \& Weyhenmeyer, C. E. (2004). IntCal04 terrestrial radiocarbon age calibration, 0-26 cal kyr BP. Radiocarbon, 46(3), 1029-1058.

Roig, F.A. (1998). La vegetación de la Patagonia. En Correa,M. N. (Ed.), Flora Patagónica. Buenos Aires: Colección Científica del Insituto Nacional de Tecnología Agropecuaria (pp. 48-166)

Roig-Juñent, S., Flores, G., Claver, S., Debandi, G. \& Marvaldi, A. (2001). Monte Desert (Argentina): insect biodiversity and natural areas. Journal of Arid Environments, 47,
77-94.

Roig, F. A., Roig-Juñent, S. \& Corbalán, V. (2009). Biogeography of the Monte Desert. Journal of Arid Environments, 73, 164-172.

Scartascini, F. L., Charo, M. \& Volpedo, A. (2009). Caracterización de las estrategias de obtención de recursos ícticos a partir del análisis de los otolitos. El caso de la costa norte del Golfo San Matías. En Santiago, F., Salemme, M., Alvarez, M., Piana, E., Vázquez, M. \& Mansur, M.E. (Eds.), Arqueología de Patagonia: una mirada desde el último confín Vol. 2 (pp. 845-852). Ushuaia: Editorial Utopías.

Schäbitz, F. (1994). Holocene climatic variations in northern Patagonia, Argentina. Palaeogeography, Palaeoclimatology, Palaeoecology, 109, 287-294.

Schäbitz, F. (2003). Estudios polínicos del cuaternario en las regiones áridas del sur de Argentina. Revista del Museo Argentino de Ciencias Naturales, 5(2), 291-299.

Schäbitz, F. \& Liebricht, H. (1998). Landscape and climate development in the south-eastern part of the "Arid Diagonal" during the last 13,000 years. Bamberger Geographische Schriften, 15, 371-388.

Smart, T., \& Hoffman, E. (1988). Environmental interpretation of archaeological charcoal. En C. Hastorf, \& V. Popper (Eds.)

Current Paleoethnobotany: Analytical methods and cultural interpretations of archaeological plant remains (pp. 167205). Chicago, United States: University of Chicago Press.

Storckmarr, J. (1971). Tablets with spores used in absolute pollen analysis. Pollen it spores 13, 165-621.

Stuiver, M. \& Reimer, P. J. (1993). Extended ${ }^{14} \mathrm{C}$ database and revised CALIB radiocarbon calibration program. Radiocarbon, 35, 215-230.

Tortorelli, L. A. (1956). Maderas y bosques argentinos. Buenos Aires, Argentina: Acme.

Stuiver, M., Reimer, P. J. \& Reimer, R. W. (2005). CALIB 5.0.2. http://calib.qub.ac.uk/calib/

Vernet, J. L. (1973). Étude sur l'histoire de la végétatation du Sud-Est de la France au Quaternaire d'après les charbons de bois principalement. Paleobiologie Continentale 4 (1), 1-90. 
